\title{
Konvergensi Pertumbuhan Ekonomi Kota dan Kabupaten Klaster Metropolitan Jawa Timur
}

\section{(Economic Growth Convergence City and District of East Java Metropolitan Cluster)}

\author{
Nanda Mutya Atmasari*, Teguh Hadi Priyono, Sebastiana Viphindrartin \\ Jurusan Ilmu Ekonomi dan Studi Pembangunan, Fakultas Ekonomi dan Bisnis, Universitas Jember (UNEJ) \\ Jln. Kalimantan 37, Jember 68121 \\ E-mail: nanmutya17@gmail.com
}

\begin{abstract}
Abstrak
Penetapan klaster kewilayahan berfungsi sebagai sasaran kebijakan pengembangan kewilayahaan dalam rangka meningkatkan pemerataan pertumbuhan ekonomi, infrastruktur, social dan budaya di seluruh Jawa Timur. Penelitian ini bertujuan untuk mengetahui apakah terjadi penurunan kesenjangan pertumbuhan ekonomi setiap tahun (konvegensi sigma) dan apakah terjadi percepatan pertumbuhan ekonomi rendah terhadap pertumbuhan ekonomi tinggi (konvergensi beta) di kota dan kabupaten klaster metropolitan Jawa Timur pada tahun 2015-2018. Penelitian ini menggunakan data sekunder. Metode analisis yang digunakan dalam penelitian ini adalah analisis konvergensi dan analisis regresi data panel. Hasil penelitian menunjukkan bahwa tidak terjadi penurunan kesenjangan pertumbuhan ekonomi setiap tahun (konvegensi sigma) dan tidak terjadi percepatan pertumbuhan ekonomi rendah terhadap pertumbuhan ekonomi tinggi (konvergensi beta) di kota dan kabupaten klaster metropolitan Jawa Timur pada tahun 2015-2018. Hasil estimasi analisis regresi untuk konvergensi beta baik absolut dan kondisional juga menunujukkan bahwa tidak terjadi konvergensi pada kota dan kabupaten di klaster metropolitan Jawa Timur pada tahun penelitian. Variable IPM dan PMTB juga ternyata belum mampu mendorong adanya konvergensi pertumbuhan ekonomi di kota dan kabupaten klaster metropolitan Jawa Timur.
\end{abstract}

Kata Kunci: pertumbuhan ekonomi, konvergensi, konvergensi sigma, konvergensi beta.

\begin{abstract}
The determination of the territorial clusters serves as the target of territorial development policies in order to increase equitable distribution of economic, infrastructure, social and cultural growth throughout East Java. This study aims to determine whether there is a decline in the economic growth gap every year (sigma convergence) and whether there is an acceleration of low economic growth to high economic growth (convergence beta) in the cities and districts of the East Java metropolitan cluster on 2015-2018. This research uses secondary data. The analytical method used in this study is convergence analysis and panel data regression analysis. The results showed that there was no decrease in the economic growth gap every year (sigma convergence) and there was no acceleration of low economic growth to high economic growth (beta convergence) in cities and districts of the East Java metropolitan cluster on 2015-2018. The estimation results of the regression analysis for beta convergence, both absolute and conditional, also show that there is no convergence in cities and districts in the East Java metropolitan cluster in the research year. The HDI and PMTB variables have not been able to encourage convergence of economic growth in cities and regencies in the metropolitan cluster of East Java.
\end{abstract}

Keywords: economic growth, convergence, sigma convergence, beta convergence.

\section{Pendahuluan}

Indonesia merupakan salah satu negara berkembang dengan wilayah kepulauan yang memiliki keberagaman dan sumber daya alam yang melimpah, sehingga setiap daerah memiliki banyak potensi dan terbagi menjadi berbagai sektor. Keberagaman potensi dari berbagai macam sektor secara tidak langsung mendorong peningkatan pertumbuhan ekonomi Indonesia melalui peningkatan pendapatan riil dari berbagai sektor yang ada. Namun, perbedaan potensi antar daerah juga menimbulkan permasalahan baru karena daya berkembang antara daerah satu dengan daerah lainnya tidak sama. Tidak jarang adanya perbedaan daya berkembang setiap daerah menyebabkan daerah kaya atau daerah ekonomi tinggi semakin kaya dan daerah miskin atau daerah ekonomi rendah semakin miskin karena tidak dapat mengejar tingkat pertumbuhan ekonomi daerah lain yang sudah tinggi. Hal tersebut menyebabkan isu kesenjangan daerah sampai saat ini

\footnotetext{
* Corresponding author
}

masih menjadi topik hangat yang sering dibahas sehingga beberapa decade terakhir pemerintah focus pada pertumbuhan dan pemerataan dalam pembangunan ekonomi Indonesia.

Bentuk focus pemerintah dalam pertumbuhan dan pemerataan dalam pembangunan ekonomi Indonesia dapat dilihat dalam pertumbuhan ekonomi pada setiap provinsi, salah satunya adalah provinsi Jawa Timur. Pendapatan Domestik Regional Bruto (PDRB) Jawa Timur hingga 2018 merupakan salah satu penyumbang pendapatan nasional tertinggi kedua setelah provinsi DKI Jakarta. Hal tersebut dapat terjadi karena adanya kebijakan pemerintah Provinsi Jawa Timur dalam menciptakan pusat-pusat kegiatan perwilayahan baru yang tersebar di seluruh Jawa Timur (RPJMD Jawa Timur, 2019 - 2024). Terdapat beberapa alasan dibalik keputusan pemerintah provinsi Jawa Timur dalam menciptakan pusat-pusat kegiatan perwilayahan yang tersebar di seluruh wilayah Jawa Timur diantaranya adalah 
sebagai upaya dalam mengembangkan wilayah dan membangun sumber-sumber pertumbuhan baru sekaligus wadah dalam memanfaatkan potensi daerah sehingga meningkatkan nilai tambah pada wilayah yang memiliki pertumbuhan ekonomi rendah. Lalu alasan yang terakhir yaitu, untuk peningkatan keterkaitan kantong-kantong produksi utama di Jawa Timur.

Adanya penetapan klaster kewilayahan yang berfungsi sebagai sasaran kebijakan pengembangan kewilayahaan dalam rangka meningkatkan pemerataan pertumbuhan ekonomi, infrastruktur, social dan budaya di seluruh Jawa Timur. Pembagian klaster kewilayahan merupakan bagian dari upaya pemerintah Jawa Timur dalam menekan kesenjangan di Jawa Timur. Salah satu klaster dalam pembagian klaster kewilayah di Jawa Timur adalah klaster metropolitan. Dalam Rancangan Pembangunan Industri Provinsi (RPIP) yang dipaparkan oleh Gubernur Jawa Timur pada rapat kordinasi antara pemerintah dengan Bank Indonesia Klaster metropolitan memiliki istilah lain yaitu wilayah ring I Jawa Timur. Sesuai dengan RPJMD Jawa Timur tahun 2019-2024 klaster metropolitan provinsi Jawa Timur yang terdiri dari kota Surabaya, kota Mojokerto, kota Pasuruan, kabupaten Gresik, kabupaten Pasuruan, kabupaten Sidoarjo, dan kabupaten Mojokerto. kota dan kabupaten wilayah ini memiliki berbagai karakter geografisnya sendiri namun masih dalam satu pola wilayah yang berdekatan. Wilayah ini terbentuk karena kesamaan sektor unggulan yaitu sektor perdagangan dan industri pengolahan (RPJMD Jawa Timur, 2019).

Sebagian besar pendapatan regional kota dan kabupaten di wilayah tersebut berasal dari sektor industri pengolahan dan perdagangan besar. Secara bersamaan klaster ini memiliki sumbangsih yang strategis terhadap berlangsungnya pertumbuhan ekonomi Jawa Timur karena pendapatan pada wilayah ini disumbang oleh sektor industri yang tinggi sesuai dengan pemikiran Sukirno (1998) bahwa pertumbuhan ekonomi terjadi ketika terdapat pertambahan jumlah dan produksi barang industri. Namun meski pendapatan regional wilayah ini di dorong oleh sektor industri pengolahan dan perdagangan besar namun tingkat PDRB riil kota dan kabupaten di wilayah ini memiliki perbedaan yang cukup tinggi seperti pada Gambar 1.

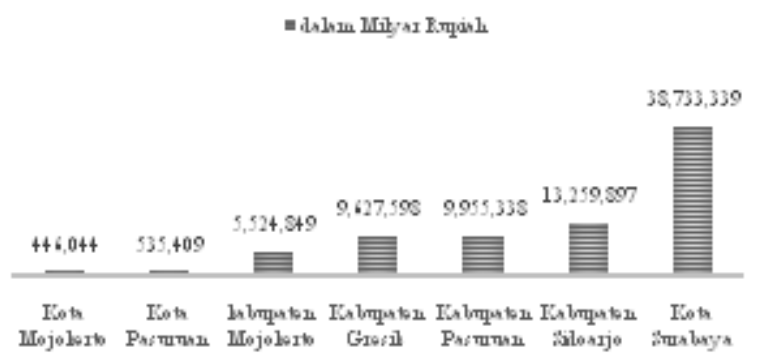

Gambar 1. Grafik total PDRB riil kota dan Kabupaten Klaster Metropolitan Jawa Timur Tahun 2018 (Sumber:BPS diolah, 2018)

Mengacu pada perbedaan statistic pertumbuhan ekonomi pada gambar 1.1 perlu adanya upaya pengejaran oleh wilayah dengan PDRB riil rendah sehingga setiap wilayah nantinya berada pada titik PDRB riil yang sama atau dengan kata lain terjadi konvergen. Upaya agar setiap wilayah dapat mengejar ketertinggalan dan mensejajarkan diri dengan wilayahwilayah yang sudah maju, baik dalam hal pendapatan, produktivitas, upah dan berbagai indicator ekonomi lainnya, sehingga gap (jurang) kesenjangan antar wilayah tersebut berkurang dalam ilmu ekonomi dapat disebut sebagai konvergensi antar wilayah (Sodik dalam Faqieh, 2016).

Secara teori menurut teori neoklasik, perekonomian berbagai wilayah akan bertemu atau konvergen secara otomatis maupun kondisional pada tingkat pendapatan yang sama dengan syarat wilayah wilayah tersebut memiliki tingkat tabungan, depresiasi, pertumbuhan angkatan kerja, dan pertumbuhan produktivitas yang sama (Todaro dan Smith, 2006). Secara empiris penelitian Herz dan Roger (1995) sejalan dengan teori neoklasik karena pada hasil penelitian mereka menemukan pada Jerman bagian barat terjadi konvergensi. Begitu pula dengan Malik (2014) yang menemukan adanya konvergensi di Indonesia setelah pelaksanaan otonomi daerah tahun 2001 - 2012. Pada penelitian Barro (2016) juga ditemukan bukti empiris konvergensi terjadi pada pertumbuhan ekonomi di negara China. Namun berbanding terbalik dengan hasil penelitian Yulisningrum dan Styastuti (2015) yang menunjukkan bahwa tidak terjadi konvergensi pada pertumbuhan ekonomi Indonesia tahun 1992 - 2012. Lalu, menurut penelitian Faqieh (2016) menemukan bahwa pada tahun 2017-2014 di Pulau Madura tidak terjadi konvergensi dilihat dari sisi konvergensi absolut maupun konvergensi bersyarat. Begitu pula pada penelitian yang dilakukan oleh Achmad (2017) yang menunjukkan bahwa pada kota dan kabupaten di provinsi Sulawesi Tengah tidak tejadi konvergensi.

Sesuai dengan latar belakang diatas maka perlu dilakukan penelitian apakah terjadi penurunan kesenjangan pertumbuhan ekonomi setiap tahun (konvegensi sigma) dan terjadi percepatan pertumbuhan ekonomi rendah terhadap pertumbuhan ekonomi tinggi (konvergensi beta) di kota dan kabupaten klaster metropolitan Jawa Timur.

\section{Metode}

\section{Rancangan atau Desain Penelitian}

Jenis penelitian yang digunakan dalam penelitian ini adalah penelitian kuantitatif, yaitu penelitian yang menekankan pada pengujian teori melalui pengukuran variabel dengan angka dan melakukan analisis data dengan prosedur statistik

\section{Jenis dan Sumber Data}

Data yang digunakan dalam penelitian ini merupakan jenis data panel dengan rentan waktu tahun 2010 - 2018. Sumber data dari penelitian ini diperoleh dari Badan Pusat Statistika serta instansi-instansi yang terkait dengan penelitian, berbagai buku literatur, jurnal, skripsi, dan sumber lainnya yang terkait.

\section{Metode Analisis Data Analisis Konvergensi}

\section{Konvergensi Sigma}

Analisis ini merupakan analisis runtut waktu untuk mengamati terjadinya konvergensitas variable pengamatan yang dilakukan dengan perhitungan koefisien variasi. Menurut Shanker, et al., dalam Achmad(2017) formula untuk menghitung koefisien variasi tiap tahunnya adalah sebagai berikut: 


$$
C V=\frac{\sqrt{\frac{\sum(Y i-\dot{Y})^{2}}{n}}}{\dot{Y}}
$$

CV adalah koefisien variasi pada tahun tertentu; Yi mewakili PDRB riil tiap kabupaten/kota tahun $i ; \quad \dot{Y}$ mewakili mean PDRB riil tahun 2010-2018; dan $\mathrm{n}$ mewakili jumlah kabupaten atau kota dalam penelitian.

\section{Konvergensi Beta}

Mengacu pada Barro dan Martin (1992) dalam konvergensi beta terdapat 2 model yaitu konvergensi beta absolut dan konvergensi beta kondisional. Model regresi data panel dengan konvergensi beta absolut adalah sebagai berikut:

$$
\ln y_{i t}=\beta_{0 \mathrm{it}}+\beta_{1} \ln y_{i t-1}+u_{i t}
$$

dimana:

$$
\begin{array}{ll}
\beta_{0} & : \text { Konstanta/intersep } \\
\beta_{1} & : \text { Koefsien Konvergensi } \\
y_{i t} & : \text { PDRB riil kabupaten/kota i tahun ke } \mathrm{t} \\
y_{i t-1} & : \text { PDRB riil kabupaten/kota i tahun t-1 } \\
u_{i t} & : \text { error term } \\
i & : \text { cross section } \\
t & : \text { time series }
\end{array}
$$

Sedangkan model regresi dengan konvergensi beta kondisional adalah sebagai berikut:

$$
\ln y_{i t}=\beta_{0 \mathrm{it}}+\beta_{1} \ln y_{i t-1}+\beta_{2} \ln X_{1 \mathrm{it}}+\beta_{3} \ln X_{2 \mathrm{it}}+u_{i t}
$$

dimana:

$$
\begin{array}{cl}
\beta_{0} & : \text { Konstanta/intersep } \\
\beta_{1} & : \text { Koefsien Konvergensi } \\
y_{i t} & : \text { PDRB riil kabupaten/kota i tahun ke } \mathrm{t} \\
y_{i t-1} & : \text { PDRB riil kabupaten/kota i tahun } \mathrm{t}-1 \\
X_{1}, X_{2} & : \text { Variabel bebas dalam penelitian } \\
u_{i t} & : \text { error term } \\
i & : \text { cross section } \\
t & : \text { time series }
\end{array}
$$

Dalam analisis konvergensi terdapat pula perhitungan untuk mengetahui tingkat percepatan suatu wilayah mengejar wiilayah lain agar semakin mendekati steady state. Perhitungan tersebut dapat dilakukan dengan rumus berikut ini:

$$
\text { Kecepatan konvergensi }=\text { koefisien } \beta \times 100
$$

\section{Analisis Regresi Data Panel}

Penelitian ini menggunakan analisis regresi data panel. Data panel atau pooled data merupakan data yang dihasilkan dari gabungan antara data antar waktu (time series) dan data antar individu (csoss-section) (Ekananda, 2015). Proses estimasi data panel memiliki beberapa model yang dapat digunakan dalam penelitian, diantaranya sebagai berikut:

\section{CEM / Common Effects Model}

CEM atau Common Effects Model biasa disebut juga dengan istilah Pooled Least Square atau PLS. CEM adalah model paling sederhana dalam data panel. Model CEM tidak memperhatikan dimensi individu atau waktu sehigga diasumsikan perilaku antarindividu akan sama dalam berbagai kurun waktu. Hal tersebut mengakibatkan nilai intersep $(\alpha)$ akan sama untuk setiap unit cross setion. Persamaan regresi model CEM dapat ditulis sebagai berikut:

$$
Y_{i t}=\alpha+X^{\prime}{ }_{i t} \beta+\varepsilon_{i t}
$$

\section{FEM / Fixed Effects Model}

FEM atau Fixed Effects Model adalah model dalam regresi data panel yang mengasumsikan bahwa terdapat efek yang berbeda pada tiap individu yang dapat dilihat pada perbedaan setiap intersepnya. Persamaan regresi dalam model FEM ini dapat ditulis sebagai berikut:

$$
Y_{i t}=\alpha_{i t}+X^{\prime}{ }_{i t} \beta+\varepsilon_{i t}
$$

Indeks $i$ pada intersep $\quad \alpha_{i}$ menunjukkan bahwa intersep masing-masing individu berbeda, namun intersep individu antarwaktu sama (time invariant). Jika terdapat korelasi antara variable bebas $X_{i t}^{\prime}$ dan karakteristik individu

$\alpha_{i}$ biasanya model pendekatan FEM banyak digunakan (Septian, 2018).

\section{REM / Random Effects Model}

REM atau Random Effects Model biasa dikenal juga dengan istilah error component model. REM berbeda dengan FEM, perbedaan karakteristik dari setiap individu ke dalam error pada model dapat dilihat melalui model REM. Persamaan regresi dengan model REM dapat dilihat sebagai berikut:

$$
\begin{aligned}
& Y_{i t}=\alpha+X_{i t}^{\prime} \beta+\left(\varepsilon_{i t}+u_{i}\right) \\
& Y_{i t}=\alpha+X_{i t}^{\prime} \beta+w_{i t}
\end{aligned}
$$

$w_{i t}$ merupakan suku error gabungan yang terdiri atas komponen error cross section $u_{i}$ dan komponen error pada model $\varepsilon_{i t} \quad$ (Septian, 2018).

Dari tiga model diatas selanjutnya dilakukan pemilihan model dengan cara pengujian menggunakan uji Chow dan uji Hausman agar model yang digunakann tepat dan sesuai.

\section{Uji Chow}

Uji Chow digunakan untuk menguji signifikansi FEM sehingga dapat diketahui apakah model FEM lebih baik digunkan daripada model CEM, dalam hal ini yang digunakan dalam megidentifikasi model adalah dengan probabilitas uji F. hipotesis dari uji ini adalah sebagai berikut:

H0 : model CEM lebih sesuai daripada model FEM

$\mathrm{H}_{1}$ : model FEM lebih sesuai daripada CEM

Apabila nilai F-statistik lebih besar dari F-tabel dan nilai peluangnya lebih kecil dari tingkan signifikansi $\alpha$, maka cukup sebagai bukti untuk menolak hipotesis nol atau dengan kata lain FEM lebih sesuai daripada CEM (Septian, 2018) 
Uji Hausman

Uji ini menggunkan statistic uji hausman yang mengikuti distrbusi chi-square untuk menentukan apakah teknik regresi data panel dengan REM lebih baik daripada FEM. Hipotesis dalam uji ini adalah sebagai berikut:

H0 : model REM lebih sesuai daripada model FEM

\section{$\mathrm{H}_{1}$ : model FEM lebih sesuai daripada REM}

Apabila nilai statistic uji ini lebih besar daripada chi-square table dan nilai peluangnya lebih kecil dari tingkat signifikansi $\alpha$, maka cukup sebagai bukti untuk menolak hipotesis nol atau dengan kata lain model FEM lebih sesuai daripada REM (septian, 2018).

\section{Hasil dan Pembahasan}

\section{Hasil}

\section{Hasil Hitung Kovergensi Sigma}

Konvergensi sigma berfungsi untuk mengukur tingkat kesenjangan ekonomi pada waktu tertentu. Konvergensi dilihat melalui dispersi pada koefisien variasi. Pada Gambar 2 menunjukkan koefisien variasi yang semakin meningkat sepanjang tahun penelitian.

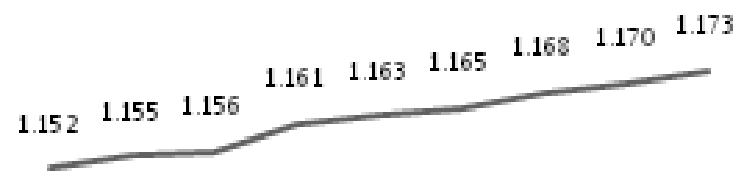

$\begin{array}{lllllllll}2010 & 2011 & 2012 & 2013 & 2014 & 2015 & 2016 & 2017 & 2018\end{array}$

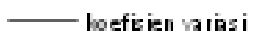

Gambar 2. Grafik konvergensi sigma kota dan kabupaten klaster metropolitan Jawa Timur (Sumber: Lampiran 3)

\section{Hasil Hitung Konvergensi Beta}

Menurut Lall dan Yilmas (2000); Paaset al. (2007) konvergensi beta memiliki dua jenis konvergensi yaitu unconditional convergence atau biasa disebut dengan konvergensi beta absolut dan conditional convergence atau konvergensi beta kondisional. konvergensi beta berfungsi untuk mengukur apakah pertumbuhan ekonomi suatu wilayah mengalami percepatan atau tidak. Dalam penelitian ini konvergensi beta dihitung menggunakan analisis regresi data panel

\section{Konvergensi Beta Absolut}

Konvergensi beta absolut merupakan kondisi konvergensi yang menganggap bahwa perekonomian diantara Negara atau wilayah yang memiliki kemiripan sebagai contoh dalam hal stuktur ekonomi, kondisi demografi, tingkat tabungan, dan variable ekonomi lainnya. Konvergensi absolut dianalisis dengan cara mengestimasi model ketika hanya pendapatan awal periode yang menjadi variable penjelas bagi pertumbuhan ekonomi. Diantara 3 model yang ada dalam regresi data panel, model yang dipilih dalam menghitung konvergensi beta absolut merupakan model fixed effect. Hasil estimasi model fixed effect dapat dilihat pada table 1 .
Tabel 1. Estimasi konvergensi beta absolut

\begin{tabular}{ccccc}
\hline Variable & Coefficient & Std. Error & t-Statistic & Prob. \\
\hline C & 8.305305 & 0.293066 & 28.33934 & 0.0000 \\
Lnyt-1 & 0.218775 & 0.028219 & 7.752641 & 0.0000 \\
\hline R $^{2}$ & 0.994743 & F-statistic & 1486.768 \\
Adjusted R & 0.994074 & Prob(F-statistic) & 0.000000 \\
$\begin{array}{c}\text { S.E. of } \\
\text { regression }\end{array}$ & 0.118800 & Durbin-Watson stat & 0.884517 \\
\hline
\end{tabular}

Persamaan model konvergensi beta absolut berdasarkan hasil estimasi model Fixed Effect pada table 1 diatas adalah sebagai berikut:

$$
\ln y_{i t}=8.305305+0.218775 \ln y_{i t-t}+u_{i t}
$$

Persamaan diatas dapat dijelaskan sebagai berikut:

a. Nilai konstanta sebesar 8.305305 memiliki arti bahwa PDRB tahun penelitian meningkat sebesar Rp 8.305305 milyar dengan asumsi variable lain bersifat konstan

b. Nilai Koefisien variable $\ln y_{i t-1}$ sebesar 0.218775 memiliki arti bahwa variable $\ln y_{i t-1}$ atau PDRB riil t-1 $_{1}$ naik sebesar Rp 100 milyar maka akan meningkatkan PDRB riil di tahun penelitian sebesar Rp 21.8775 milyar dengan asumsi variable lain konstan

Berdasarkan nilai koefisien PDRB riil $\mathrm{t}_{\mathrm{t}-1}$ tingkat percepatan suatu wilayah mengejar wilayah lain agar semakin mendekati steady state adalah sebesar $21 \%$.

Pengaruh setiap variable independen secara individu maupun keseluruhan terhadap variable dependen berdasarkan probabilitas t-statistic dan F-statistic hasil estimasi regresi data panel pada table 1 menunjukkan bahwa variable

$\ln y_{i t-1} \quad$ berpengaruh secara signifikan dengan probabilitas sebesar 0.0000 lebih kecil dari nilai $\alpha 0.05$

\section{Konvergensi Beta Kondisional}

Konvergensi beta kondisional beranggapan bahwa karakteristik structural antar wilayah memiliki ketidaksamaan sehingga konvergensi dipengaruhi oleh structural wilayah tersebut. Hal tersebut yang menjadikan konvergensi beta kondisional perlu ditambahkan beberapa variable penjelas yang diperkirakan berpengaruh terhadap pertumbuhan ekonomi. Dalam persamaan ini ditambahkan variable Indeks Pembangunan Manusia (IPM) dan Pembentukan Modal Tetap Bruto (PMTB). Diantara 3 model yang ada dalam analisis regresi data panel, model yang paling baik merupakan model fixed effect. Hasil estimasi model fixed effect dapat dilihat pada table 2 .

Tabel 2. Estimasi konvergensi beta kondisional

\begin{tabular}{ccccc}
\hline Variable & Coefficient & Std. Error & t-Statistic & Prob. \\
\hline C & -12.93309 & 1.822105 & -7.097881 & 0.0000 \\
Lnyt-1 & 0.018782 & 0.020676 & 0.908424 & 0.3678 \\
Ln IPM & 5.511647 & 0.459298 & 12.00014 & 0.0000 \\
Ln PMTB & -0.033302 & 0.006003 & -5.547133 & 0.0000 \\
\hline R $^{2}$ & 0.998807 & F-statistic & 4932.095 \\
Adjusted R & 0.998605 & Prob(F-statistic) & 0.000000 \\
$\begin{array}{c}\text { S.E. of } \\
\text { regression }\end{array}$ & 0.057642 & Durbin-Watson stat & 0.490517 \\
\hline
\end{tabular}


Persamaan model konvergensi beta kondisional berdasarkan hasil estimasi model Fixed Effect pada table 2 diatas adalah sebagai berikut:

$$
\begin{gathered}
\ln y_{i t}=-12.93309+0.018782 \ln y_{i t-t}+5.511647 \ln I P M_{i t} \\
-0.03302 \ln P M T B_{i t}+u_{i t}
\end{gathered}
$$

Persamaan diatas dapat dijelaskan sebagai berikut:

a. Nilai konstanta sebesar -12.93309 memiliki arti bahwa PDRB tahun penelitian menurun sebesar Rp 12.93309 milyar dengan asusmsi variable lain bersifat konstan

b. Nilai Koefisien variable $\ln y_{i t-1}$ sebesar 0.018782 memiliki arti bahwa variable $\ln y_{i t-1}$ atau PDRB riil $\mathrm{t}_{\mathrm{t}-1}$ naik sebesar Rp 100 milyar maka akan meningkatkan PDRB riil di tahun penelitian sebesar Rp 1.8782 milyar dengan asumsi variable lain konstan

c. Nilai Koefisien variable $\ln I P M_{i t}$ sebesar 5.511647 memiliki arti bahwa variable $\ln I P M_{i t}$ atau IPM tahun penelitian naik sebesar 1 poin maka akan meningkatkan PDRB riil di tahun penelitian sebesar Rp 5.511647 milyar dengan asumsi variable lain konstan

d. Nilai Koefisien variable $\ln P M T B_{i t}$ sebesar -0.03302 memiliki arti bahwa variable $\ln P M T B_{i t}$ atau PMTB tahun penelitian naik sebesar Rp 100 juta maka akan menurunkan PDRB riil di tahun penelitian sebesar Rp 3.302 milyar dengan asumsi variable lain konstan

Berdasarkan nilai koefisien PDRB riil ${ }_{\mathrm{t}-1}$ tingkat percepatan suatu wilayah mengejar wilayah lain agar semakin mendekati steady state adalah sebesar $1.8 \%$.

Pengaruh setiap variable independen secara individu terhadap variable dependen berdasarkan probabilitas t-statistic hasil estimasi pada table 2 didapatkan hasil sebagai berikut:

a. Nilai Probabilitas variable $\ln y_{i t-1}$ sebesar 0.3678 memiliki arti bahwa variable $\ln y_{i t-1}$ atau PDRB riil tidak memiliki pengaruh signifikan terhadap PDRB riil di tahun penelitian karena nilai probabilitas lebih besar daripada nilai $\alpha 0.05$. Hal tersebut tentu bertolak belakang dengan hasil estimasi konvergensi beta absolute yang menunjukkan bahwa variable ini signifikan berpengaruh terhadap PDRB riil tahun penelitian.

b. Nilai Probabilitas variable $\ln I P M_{i t}$ sebesar 0.0000 memiliki arti bahwa variable $\ln I P M_{i t}$ atau IPM tahun penelitian Berpengaruh signifikan terhadap PDRB riil di tahun penelitian karena nilai probabilitas $\mathrm{t}$ lebih kecil daripada nilai $\alpha$ sebesar 0.05 .

c. Nilai Probabilitas variable $\ln P M T B_{i t}$ sebesar 0.0000 memiliki arti bahwa variable $\ln P_{M T B_{i t}}$ atau PMTB berpengaruh signifikan terhadap PDRB riil di tahun penelitian karena nilai probabilitas t lebih kecil daripada nilai $\alpha$ sebesar 0.05 .

Sedangkan berdasarkan probabilitas F-statistic sebesar 0.000000 atau lebih kecil dari nilai $\alpha$ sebesar 0.05 artinya secara keseluruhan variable IPM dan PMTB berpengaruh signifikan terhadap PDRB riil tahun penelitian.

\section{Pembahasan \\ Konvergensi Sigma Kota dan Kabupaten Klaster Metropolitan Jawa Timur}

Berdasarkan Gambar 2 koefisien variasi PDRB riil menunjukkan trend yang meningkat. Koefisien variasi pada tahun 2010 menunjukkan nilai sebesar 1.152 dan secara konsisten meningkat hingga pada tahun 2018 menunjukkan nilai sebesar 1.173. Trend koefisien variasi PDRB riil yang meningkat mengindikasikan bahwa terdapat peningkatan kesenjangan/ketimpangan PDRB riil antar kota dan kabupaten di klaster metropolitan Jawa Timur. Semakin besar nilai koefisien variasi PDRB riil maka semakin tinggi kesenjangan atau ketimpangan PDRB riil antar kota dan kabupaten klaster metropolitan Jawa Timur.

Hal tersebut dapat terjadi karena adanya perbedaan daya berkembang antar kota dan kabupaten dalam mengelola potensi serta sumber daya alam. Selain itu, kota Surabaya sebagai kota dengan PDRB riil tertinggi belum mencapai titik maksimum yang stagnan sehingga perekonomian PDRB riil di wilayah ini terus meningkat sepanjang tahun. Oleh karena itu meskipun PDRB riil pada tiap kota dan kabupaten yang memiliki tingkat PDRB riil dibawah kota Surabaya meningkat setiap tahunnya kesenjangan atau ketimpangan pertumbuhan ekonomi di klaster metropolitan Jawa Timur tetap tinggi bahkan cenderung meningkat sepanjang tahun penelitian sesuai hasil penelitian pada gambar 2 .

Trend koefisien variasi PDRB riil yang meningkat menunjukkan bahwa di kota dan kabupaten klaster metropolitan Jawa Timur tidak terjadi konvergensi sigma. Karena terjadi disvergensi sigma maka penelitian berbanding terbalik terhadap hipotesis penelitian. Hal serupa ditemukan dalam penelitian Achmad (2017) yang menyatakan bahwa di kabupaten/kota Provinsi Sulawesi Tengah tahun 2010-2014 tidak ditemukan adanya konvergensi sigma. Penelitian ini berbanding terbalik dengan penelitian Fashollatain (2014) yang menunjukkan trend menurun pada hasil analisis konvergensi sigma pertumbuhan ekonomi di Indonesia. Penelitian ini juga memberikan bukti bahwa perokonomian suatu wilayah tidak secara otomatis mengalami konvergensi sesuai dengan teori neoklasik Solow.

\section{Konvergensi Beta Kota dan Kabupaten Klaster Metropolitan Jawa Timur}

Menurut Lall dan Yilmas (2000); Paaset al. (2007) konvergensi beta memiliki dua jenis konvergensi yaitu unconditional convergence atau biasa disebut dengan konvergensi beta absolut dan conditional convergence atau konvergensi beta kondisional. Ketika mengestimasi konvergensi beta absolut peneliti menggunakan PDRB riil sebagai variable dependen dan PDRB riil $\mathrm{t}_{\mathrm{t}-1}$ sebagai variable independen. Berdasarkan hasil estimasi pada table 1 menunjukkan nilai koefisien pada variable PDRB riil $\mathrm{t}_{\mathrm{t}-1}$ sebesar 0.218775. Dalam persamaan hasil estimasi model konvergensi beta absolut menunjukkan hubungan positif antara PDRB riil $t_{\mathrm{t}-1}$ dengan PDRB tahun 2010-2018. Hubungan positif dalam persamaan tersebut memiliki arti bahwa wilayah dengan PDRB riil rendah atau pertumbuhan ekonomi rendah belum mampu mengejar wilayah dengan PDRB riil tinggi atau pertumbuhan ekonomi tinggi. Koefisien 
PDRB riil $\mathrm{t}_{\mathrm{t}-1}$ yang positif menandakan terjadinya divergensi pada pertumbuhan ekonomi kota dan kabupaten klaster metropolitan Jawa Timur karena adanya gap pertumbuhan yang semakin besar sehingga perekonomian justru menjauh dari kondisi steady state.

Gap pertumbuhan yang semakin besar tersebut disebabkan karena adanya perbedaan daya berkembang tiap kota dan kabupaten di klaster metropolitan Jawa Timur. Kota dan kabupaten di wilayah ini memiliki kesamaan sektor pendukung PDRB riil tertinggi berasal dari sektor industri dan perdagangan besar, namun hal tersebut belum cukup untuk mendorong daya berkembang sektor-sektor lain sehingga terdapat perbedaan daya berkembang dari sektorsektor yang lain dan menyebabkan kota atau kabupaten dengan pertumbuhan ekonomi tinggi tetap tidak dapat dikejar. Dari ke tujuh daerah yang termasuk dalam klaster metropolitan hanya Mojokerto yang memiliki sektor pertanian dengan jumlah besar lalu hanya kabupaten Gresik yang memiliki sektor pertambangan dengan jumlah besar dan hanya kota Surabaya yang memiliki sektor penyedia akomodasi dan makan minum dengan jumlah besar. Sedangkan Kabupaten Sidoarjo dan Pasuruan memiliki sektor konstruksi dengan jumlah besar.

Berdasarkan asumsi the law of diminishing return konvergensi terjadi ketika terdapat hubungan negative antara PDRB riil dengan PDRB riil $\mathrm{t}_{-1}$. Dengan asumsi tersebut wilayah dengan pertumbuhan ekonomi tinggi mencapai kondisi steady state sehingga wilayah dengan pertumbuhan ekonomi rendah dapat mengejar ketertinggalannya. Seperti yang dapat dilihat pada gamabr 1 kota Surabaya merupakan wilayah dengan pertumbuhan ekonomi tertinggi diantara kota dan kabupaten yang berada pada klaster metropolitan. Setiap tahun PDRB riil kota Surabaya mengalami peningkatan yang mengartikan bahwa perkonomian kota Surabaya belum berada pada kondisi steady state.Singkatnya, pertumbuhan ekonomi kota Surabaya belum stagnan pada satu titik tertingginya sehingga kota dan kabupaten yang memiliki tingkat pertumbuhan ekonomi dibawah kota Surabaya belum mampu mengejar ketertinggalannya (divergensi).

Sebagaimana hasil analisis konvergensi beta absolut, pada hasil estimasi konvergensi beta kondisional juga menunjukkan nilai positif sebesar 0.018782 dengan kecepatan pertumbuhan ekonomi sebesar 1,8\% untuk menuju perekonomian steady state. Hasil positif tersebut menandakan bahwa berdasarkan hasil estimasi konvergensi beta kondisional juga tidak terjadi konvergensi sama dengan konvergensi beta absolut. Dalam konvergensi beta kondisional ditambahkan variable independen lain selain PDRB riil $t_{t-1}$ yaitu Indeks Pembangunan Manusia dan Pembentukan Modal Tetap Bruto. Hasil estimasi variable IPM dalam penelitian ini memiliki pengaruh positif terhadap PDRB riil kota dan kabupaten klaster metropolitan Jawa Timur. Pengaruh positif tersebut mengindikasikan ketika Indeks Pembangunan Manusia naik maka pertumbuhan ekonomi yang dicerminkan dengan PDRB riil juga mengalami kenaikan. Indeks Pembangunan Manusia yang tinggi menandakan kualitas sumber daya manusia yang tinggi. Tingginya kualitas sumber daya manusia dapat menghasilkan produk barang dan jasa yang berkualitas serta memiliki daya saing tinggi sehingga dapat meningkatkan PDRB riil suatu wilayah. Dengan adanya dampak tersebut penduduk dapat menyerap dan mengelola sumber daya yang penting bagi pertumbuhan ekonomi.

Ketika kualitas sumber daya manusia tinggi faktor-faktor produksi yang lain akan mampu digunakan secara maksimal. Penduduk yang berkualitas tinggi akan mampu berinovasi untuk mengembangkan faktor-faktor produksi yang sudah ada sehingga dapat menghasilkan produk yang maksimal. Oleh karena itu, ketika kualitas sumber daya manusia tinggi maka produktivitas meningkat dan meningkatkan pendapatan. Produktivitas dan pendapatan yang meningkat tersebut dapat mempercepat pertumbuhan ekonomi. Kenaikan IPM tidak hanya memiliki dampak langsung terhadap pertumbuhan ekonomi, namun memiliki dampak tidak langsung dalam menjaga pertumbuhan ekonomi jangka panjang.

Sedangkan berdasarkan hasil estimasi variable PMTB memiliki hubungan negative terhadap PDRB riil kota dan kabupaten klaster metropolitan Jawa Timur. Hubungan negative tersebut memiliki makna bahwa ketika terjadi kenaikan investasi untuk modal fisik maka akan menurunkan pertumbuhan ekonomi kota dan kabupaten klaster metropolitan Jawa Timur. Hubungan terbalik antara PMTB dan PDRB riil tersebut mencerminkan bahwa ketika pemerintah melakukan pengeluaran untuk investasi modal fisik maka PDRB riil kota dan kabupaten klaster metropolitan Jawa Timur mengalami penurunan. Penurunan PDRB riil dapat terjadi ketika pendapatan pemerintah sebagian besar dialokasikan untuk pembiayaan investasi modal fisik. Adanya perbedaan pengeluaran pemerintah dalam melakukan pembiayaan investasi modal fisik juga menjadi penyebab lain tidak mampunya variable PMTB mempercepat pertumbuhan ekonomi sehingga konvergensi dapat terjadi di Kota dan Kabupaten Klaster Metropolitan Jawa Timur.

Jumlah pengeluaran pemerintah untuk investasi modal fisik wilayah dengan pertumbuhan ekonomi rendah belum mampu melampaui jumlah investasi modal fisik wilayah dengan pertumbuhan ekonomi tinggi. Kota Surabaya menduduk merupakan kota dengan pembiayaan modal tertinggi diantara kota yang lainnya. Hingga pada tahun 2018 kota Surabaya menduduki posisi tertinggi dengan pembiayaan modal hingga ratusan juta sedangkan kota dan kabupaten lain yang hanya mampu melakukan pembiayaan modal sebesar puluhan atau belasan juta saja. Bahkan kota Mojokerto dan kota Pasuruan hanya mampu melakukan pembiayaan modal sekitar satu juta rupiah saja. Terdapat perbedaan jumlah pembiayaan modal yang cukup tinggi antar kota dan kabupaten menyebabkan percepatan pertumbuhan ekonomi tidak dapat terjadi di wilayah tersebut. Sekalipun pengeluaran pemerintah untuk investasi modal fisik di wilayah dengan pertumbuhan ekonomi rendah melampaui jumlah pengeluran pemerintah untuk investasi modal fisik, investor lebih memilih untuk berinvestasi di wilayah yang memiliki pertumbuhan ekonomi tinggi.

Hasil hitung konvergensi beta absolut dan konvergensi beta kondisional yang menunjukkan tidak terjadinya percepatan pertumbuhan ekonomi di daerah dengan pertumbuhan ekonomi rendah terhadap daerah dengan pertumbuhan ekonomi tinggi atau konvergensi beta. Oleh karena hasil penelitian ini menunjukkan tidak terjadi konvergensi beta baik konvergensi beta absolut dan konvergensi beta kondisional di Kota dan Kabupaten Klaster Metropolitan 
Jawa Timur maka penelitian ini tidak sesuai dengan hipotesis yang ada. Hasil penelitin ini serupa dengan penelitian Yulisningrum dan Setyastuti (2015) dimana dalam penelitiannya juga tidak menemukan adanya konvergensi beta absolut maupun kondisional di Indonesia pada tahun 1992-2012. Penelitian ini juga memberikan bukti bahwa secara kondisonal perokonomian suatu wilayah tidak mengalami konvergensi sesuai dengan teori neoklasik Solow.

\section{Simpulan}

Berdasarkan hasil penelitian dapat diambil kesimpulan sebagai berikut:

1. Hasil estimasi menunjukkan bahwa tidak terjadi penurunan kesenjangan pertumbuhan ekonomi setiap tahun atau konvergensi sigma di kota dan kabupaten klaster metropolitan Jawa Timur pada tahun penelitian. Koefisien variasi menunjukkan bahwa ternyata kesenjangan pertumbuhan ekonomi meningkat sepanjang tahun penelitian.

2. Hasil estimasi analisis regresi untuk konvergensi beta baik absolut dan kondisional juga menunujukkan bahwa tidak terjadi konvergensi pada kota dan kabupaten di klaster metropolitan Jawa Timur pada tahun penelitian. Variable IPM dan PMTB juga ternyata belum mampu mendorong adanya konvergensi pertumbuhan ekonomi di kota dan kabupaten klaster metropolitan Jawa Timur.

\section{Referensi}

Achmad, Lustiawaty. 2017. Analisis Konvergensi dan Keterkaitan Spasial Perumbuhan Ekonomi Kabupaten/Kota di Sulawesi Tengah. Sulawesi tengah: Unversitas Tadulako

Adha, Rishan., Wahyunandi. 2015. Disparitas dan Konvergensi Pertumbuhan Ekonomi antar Kabupaten dan Kota di Provinsi Nusa Tenggara Barat. Mataram Universitas Mataram

Arsyad, Lincolin. 2010. Ekonomi Pembangunan; Edisi Kelima. Yogyakarta: STIM YKPN

Barro, Robert J., Sala-i-Martin, Xavier. 1991. "Convergence Across States and Regions". Brookings Papers on Economic Activity

Barro, Robert J., Sala-i-Martin, Xavier. 1992. “Convergence”. Journal of Political Economy.

Ekananda, Mahyus. 2015. Ekonometrika Dasar: Untuk Penelitian Ekonomi, Sosial dan Bisnis. Jakarta: Mitra Wacana Media

Jhingan, M.L.2002. Ekonomi Pembangunan dan Perencanaan. Jakarta: Raja Grafindo Persada

Lall, Somik., Yilmaz,Sedar. 2000. "Regional Economic Convergence: Do Policy Instruments Make a Difference?”. Washington:IBRD. World Bank Institute

Paas, Tiiu, Andres Kuusk, Friso Schlitte, dan Andres Vork. 2007. Econometric Analysis of Income in Selected EU Countries and Their NUT 3 Level Regions. Turki:Tartu University Press

Sukirno, Sadono. 1998. Pengantar Ekonomi Makro. Jakarta: PT Raja Grasindo Persada.

Todaro, Michael P., Smith, Stephen C. 2006. Pembangunan Ekonomi Edisi Kesembilan. Jakarta: Erlangga

Yulisningrum, Chatarina A.A., Setyastuti, A.M. 2015. Analisis Konvergensi Pertumbuhan EKonomi di Indonesia Tahun 1992 - 2012. Yogyakarta: Universitas Atma Jaya. 